\title{
MACUMBA PARA ALÉM DOS MUROS DO TERREIRO
}

\author{
MACUMBA BEYOND THE TERREIRO WALLS
}

\section{MACUMBA MÁS ALLÁ DE LAS PAREDES DE TERREIRO}

\author{
Cristiano Sant'Anna ${ }^{1}$ \\ Isadora Souza da Silva ${ }^{2}$ \\ Stela Guedes Caputo ${ }^{3}$
}

\section{RESUMO}

O termo macumba tem sido usado pejorativamente, como um insulto. Pretende-se, com ele, agredir religiões como umbanda, candomblé e cultos afro-diaspóricos de maneira geral. A ofensa verbal é parte do racismo estrutural da sociedade brasileira. Tão estrutural e tão alargado é o racismo, que possui várias máscaras da mesma face colonial, uma delas: o racismo religioso. No contexto atual, na nossa contemporaneidade, com o avanço das tecnologias e com as mudanças nas dinâmicas comunicacionais em rede, associado às táticas de luta antirracistas, outros espaços ganham protagonismo para difusão das religiões de matriz africana no Brasil, que extrapolam os muros dos terreiros, entre eles, as redes sociais da internet. Entendemos que esse contexto também se potencializa pela produção e consumo de imagens. Desta maneira, clicar, postar, curtir, comentar e compartilhar faz parte do nosso dia a dia na/da "Sociedade do compartilhamento" (SANT'ANNA, 2017), não somente como seguidores de páginas e perfis, mas como "imaginantes" (CAPUTO e SANT'ANNA, 2018). Assim, os macumbeiros têm ressignificado sua atuação para além dos muros dos terreiros. Partindo da Educação nos terreiros (CAPUTO,2012) pensamos para esse dossiê, artigos e pesquisas que versam sobre religiosidades afrodiaspóricas como também no entrecruzamento dos fenômenos da ciberculturas, tais como as redes sociais da internet.

\section{ABSTRACT}

The term macumba has been used pejoratively, as an insult. It is intended, with it, to attack religions such as Umbanda, Candomblé and Afro-Diasporic cults in general. Verbal offense is part of the structural racism of Brazilian society. So structural and so broad is racism, which has several masks of the same colonial face, one of them: religious racism. In the current context, in our contemporaneity, with the advancement of technologies and changes in network communication dynamics, associated with anti-racist tactics, other spaces gain prominence for the dissemination of African-based religions in Brazil, which go beyond the walls of the terreiros, among them, internet social networks. We understand that this context is also enhanced by the production and consumption of images. In this way, clicking, posting, liking, commenting and sharing is part of our daily life in/of the "Sharing Society" (SANT'ANNA, 2017), not only as followers of pages and profiles, but as "imaginers" ( CAPUTO and SANT'ANNA, 2018). Thus, the Macumbeiros have given new meaning to their activities beyond the walls of the terreiros. Starting from Education in the terreiros (CAPUTO, 2012), we thought for this dossier,

\footnotetext{
1 Pós Doutorando em Educação, Doutor e Mestre em Educação pelo PROPED/UERJ. Vice coordenador e pesquisador do Grupo de Pesquisa Kékeré (PROPED/UERJ/CNPQ). Membro pesquisador do Grupo de Pesquisa Currículo, Narrativas Audiovisuais e Diferença (CUNADI), Professor e Coordenador Pedagógigo SEEDUC/RJ.

${ }^{2}$ Doutoranda em Educação do Grupo de Pesquisa Kékeré 9PROPED/UERJ) Professora da Rede municipal do Rio de Janeiro. Bolsista Capes.

${ }^{3}$ Professora da Faculdade de Educação (UERJ) e do Programa de Pós Graduação em Educação da UERJ (PROPED). Coordenadora do Grupo de Pesquisa Kékeré (PROPED/UERJ/CNPQ).
} 


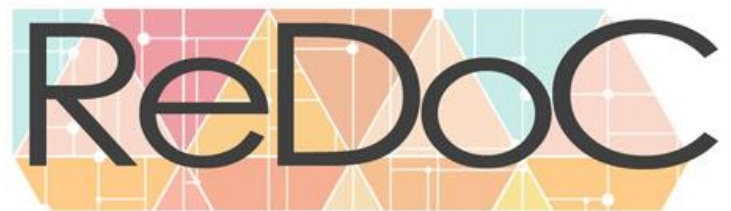

\section{Revista Docência e Cibercultura}

articles and research that deal with aphrodiasporic religiosities as well as the intersection of cyberculture phenomena, such as internet social networks.

\section{RESUMEN}

El término macumba se ha utilizado peyorativamente, como un insulto. Se pretende, con ello, atacar religiones como la umbanda, el candomblé y los cultos afro-diaspóricos en general. La ofensa verbal es parte del racismo estructural de la sociedad brasileña. Tan estructural y tan amplio es el racismo, que tiene varias máscaras del mismo rostro colonial, una de ellas: el racismo religioso. En el contexto actual, en nuestra contemporaneidad, con el avance de las tecnologías y los cambios en la dinámica de la comunicación en red, asociados a las tácticas antirracistas, cobran protagonismo otros espacios para la difusión de las religiones de base africana en Brasil, que van más allá de los muros de la terreiros, entre ellos, las redes sociales de internet. Entendemos que este contexto también se ve reforzado por la producción y consumo de imágenes. De esta forma, hacer clic, publicar, dar me gusta, comentar y compartir es parte de nuestra vida diaria en / de la "Sharing Society" (SANT'ANNA, 2017), no solo como seguidores de páginas y perfiles, sino como "imaginadores" ( CAPUTO y SANT'ANNA, 2018). Así, los Macumbeiros han dado un nuevo significado a sus actividades más allá de los muros de los terreiros. A partir de La educación en los terreiros (CAPUTO, 2012), pensamos para este dossier, artículos e investigaciones que abordan las religiosidades afrodiaspóricas así como la intersección de los fenómenos de la cibercultura, como las redes sociales de internet.

\section{"Será que já raiou a liberdade Ou se foi tudo ilusão Será, oh, será Que a lei áurea tão sonhada Há tanto tempo assinada Não foi o fim da escravidão \\ Hoje dentro da realidade Onde está a liberdade Onde está que ninguém viu" (Samba da Mangueira - 1988)}

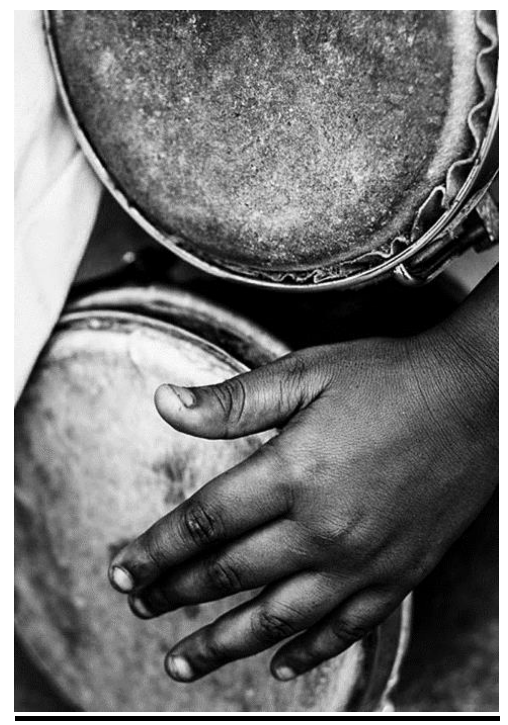

Figura 1. Toca tambor Fonte: Stela Caputo. 
Iniciamos nosso texto com estrofes da letra do samba da Estação Primeira de Mangueira ${ }^{4}$, de 1988, ano do centenário abolição da escravatura, nesse que foi o último país a terminar com o trabalho escravo nas Américas. Ao escrever esse texto, no mês de maio de 2021, 33 anos após o ano do centenário, essas duas estrofes ainda ecoam de forma cotidiana nas periferias, becos, vielas e presídios do nosso país. Como diz a música do Rappa "todo camburão tem um pouco de navio negreiro".

Nesse contexto, não podemos deixar de lembrar que o Carnaval, com seus batuques de origem africana, é a festa mais popular do nosso país, especialmente da cidade do Rio de Janeiro, e não pode acontecer no ano de 2021 por medidas sanitárias. Estamos vivendo uma pandemia há mais de um ano (COVID 19), o que nos limita a circulação e nos impede a aglomeração. Pandemia esta, que tem feito muitas vítimas fatais. No momento em que estamos fechando esse texto, mais de 500 mil mortes foram registradas no nosso país, dirigido por um governante negacionista que intensifica não somente o genocídio negro, comum nas favelas, mas da população que ainda aguarda por uma vacina para poder se imunizar.

Vivemos num país estruturado pelo racismo e forjado pelo mito da democracia racial, que desqualifica e não valoriza suas raízes africanas e ameríndias, sob diversos aspectos, principalmente culturais e religiosos. Por isso, complementamos nosso parágrafo, com outra estrofe do mesmo samba, na qual enfatizamos: "Moço - Não se esqueça que o negro também construiu - As riquezas do nosso Brasil “.

Joseph Miller, ex-presidente da Associação de Estudos Africanos dos Estados Unidos e da Associação Americana de História, abordando o tema da escravidão (2007), aponta que a escravidão moderna é produto do desenvolvimento comercial no Atlântico. Miller afirma que segundo dados levantados pelo professor David Eltis, houve em torno de 37 mil viagens carregando escravos da África às Américas do Norte e do Sul. É quase certo, diz ele, que o número de escravos da África, dos escravizados desembarcados nas Américas, seja por volta de 11 milhões.

Nesse processo da diáspora forçada Africana para terras brasileiras, por mais de três séculos, a colonização lhes impunha regras, na tentativa de aniquilar as suas raízes, seus nomes, sua cultura, sua identidade. É dito que ao sair de África os negros escravizados tinham que passar por um ritual de despedida na "árvore do esquecimento", ritual este que consistia em dar sete voltas ao redor dessa árvore, e deixar para trás, toda sua pertença identitária com o continente

\footnotetext{
${ }^{4}$ Escola de samba do Rio de Janeiro, situada no morro de Mangueira, zona norte do Rio, considerado berço do samba carioca.
} 


\section{Revista Docência e Cibercultura}

africano, sua pátria mãe, ou seja, sua ancestralidade e seus cultos, tão fortes e presentes no lado de lá do Atlântico.

Subvertendo esse paradigma colonizador, como num gingado de samba ou da capoeira, o culto a ancestralidade sobreviveu, deu forças para homens e mulheres, de diferentes idades e etnias, a resistirem e se misturou a cultura local, transformando-se num grande sistema religioso e cultural da diáspora. Mesmo com toda perseguição sofrida na colonização e no póscolonização, até a nossa contemporaneidade, esses cultos, ainda permanecem é os dias atuais, nas chamadas religiões de matriz africana ou popularmente conhecidas como "macumba".

O termo macumba tem sido usado pejorativamente, como um insulto. Pretende-se, com ele, agredir religiões como umbanda, candomblé e cultos afro-diaspóricos de maneira geral. A ofensa verbal é parte do racismo estrutural da sociedade brasileira. Tão estrutural e tão alargado é o racismo, que possui várias máscaras da mesma face colonial, uma delas: o racismo religioso. (CAPUTO, 2012, 2020; SANT'ANNA, 2020)

Nesse entendimento, podemos observar que as religiões de matriz africana, como as já destacadas, são as mais atingidas e mais discriminadas cotidianamente, com ataques ferozes de grupos religiosos cristãos, mais popurlamente conhecidos como "evangélicos".

Essas religiões, trazida por grupos africanos que chegaram ao Brasil no processo da maior diáspora forçada do mundo, o tráfico de escravos, têm toda essa discriminação por ser uma religião proveniente de negros escravizados, que por estratégias de poder e de dominação foram considerados inferiores por sua cor de pele, seu continente, sua cultura e seu modo de relacionar-se com o divino e sua ancestralidade, se contrapondo à religião hegemônica, inicialmente o catolicismo e contemporanemente também com os evengélicos, como já mencionamos.

É importante destacar que, a resistência em aceitar o outro e a tentativa de conversão deste não se resume apenas a estratégias e posturas religiosas. Podemos enxergar nessas ações uma explícita negação do que advém da cultura africana negra, logo um dos componentes do racismo estrutural que compõe nossa sociedade e que naturaliza o racismo religioso. Converter, salvar, cristianizar não se limita apenas a estratégias proselitistas quando estamos nos referindo a povos pretos. Se trata de uma evidente tentativa de demonização, de destruição, de aniquilamento de tudo que pertence a cultura negra. 
Em recente artigo, Sant'Anna e Silva (2020) destacam que, segundo fontes do Ministério da Mulher, Família e Diretos Humanos, mostrados em reportagem do Jornal O Globo ${ }^{\mathbf{5}}$, de 26 de janeiro de 2019, embora os números de intolerância religiosa, de forma geral, tenham diminuído, os casos de intolerância contra religiões de matriz africana têm aumentado de forma significante, cerca de $47 \%$, nos últimos tempos, principalmente, no Rio de Janeiro, que configura como o terceiro estado do Brasil com maior número de casos de intolerância religiosa (SANT'ANNA; SILVA, 2020, p. 130. Grifo nosso).

Partindo do contexto da escravidão e discriminação sofrida pelos africanos desde que aportaram em terras brasileiras, ratificamos assim a necessidade de utilizar o termo racismo religioso ao invés de intolerância religiosa, concordando com o pesquisador e Babalorixá Sidnei Nogueira: "o objeto do racismo já não é o homem particular, mas certa forma de existir. Trata-se da negação de uma forma simbólica e semântica de existir, de ser e estar no mundo". (NOGUEIRA, 2020, p. 91). Ainda nas palavras do pesquisador:

Nesse caso, o racismo atinge explícita ou implicitamente a dimensão mais importante de uma pessoa e/ou de uma coletividade: a sua própria humanidade. O processo de demonização dos cultos de matrizes africanas, em última análise, caracteriza a negação da humanidade desses fiéis (NOGUEIRA, 2020, p. 91).

O racismo religioso, conforme Nogueira (2020), condena a origem, a existência, a relação entre uma crença e uma origem preta. Para o pesquisador, o racismo ${ }^{6}$ não incide somente sobre pretos e pretas praticantes dessas religiões, mas sobre as origens da religião, sobre as práticas, sobre as crenças e sobre os rituais. Ainda em suas palavras, "trata-se da alteridade condenada à não existência. Uma vez fora dos padrões hegemônicos, um conjunto de práticas culturais, valores civilizatórios e crenças não pode existir, ou pode, desde que a ideia de oposição semântica a uma cultura eleita como padrão, regular e normal, seja reiteradamente fortalecida" (NOGUEIRA, 2020, p. 89).

Franz Fanon (2008), é um autor fundamental para compreendermos o quanto a imagem autodepreciativa do colonizado, mais notadamente das populações negras, foi uma das

\footnotetext{
${ }^{5}$ Fonte: <https://oglobo.globo.com/sociedade/denuncias-de-ataques-religioes-de-matriz-africana-sobem-47-nopais-23400711>. Acesso em: 14/09/2019.

${ }^{6}$ Sabemos que, aqui, Nogueira (2020) se refere ao racismo religioso. Fazemos questão de frisar porque pode parecer que o pesquisador estaria se referindo a racismo reverso, ou seja, a um inexistente racismo de brancos contra negros, pois sim, o RACISMO incide apenas sobre pretos e pretas. O racismo abordado tanto pelo autor e com o qual concordamos, é especificamente o racismo religioso.
} 
poderosas armas do colonizador e, ainda hoje, apesar de muitas mudanças, é arma da colonialidade.

Ou ainda, segundo Césaire (2000), com quem Fanon dialogou (e discordou também) a "colonização" não está somente na evangelização, ou num projeto divinizado de salvação pela glória maior de Deus, muito menos na suposta tentativa de estender a regra do Direito. A colonização é entendida como a coisificação dos corpos colonizados, a objetificação do ser ao ter suas "culturas espezinhadas, $[\ldots]$ instituições minadas, $[\ldots]$ terras confiscadas, $[. .$.$] religiões$ assassinadas, [...] magnificências artísticas aniquiladas, [...] extraordinárias possibilidades suprimidas (Césaire,2000, p. 43). A colonização de seus corpos foi uma tentativa de roubarlhes os sonhos, de afastar-lhes de seus deuses, de suas terras, de seus costumes, isto é, de suas vidas".

\section{POR QUE MACUMBA?}

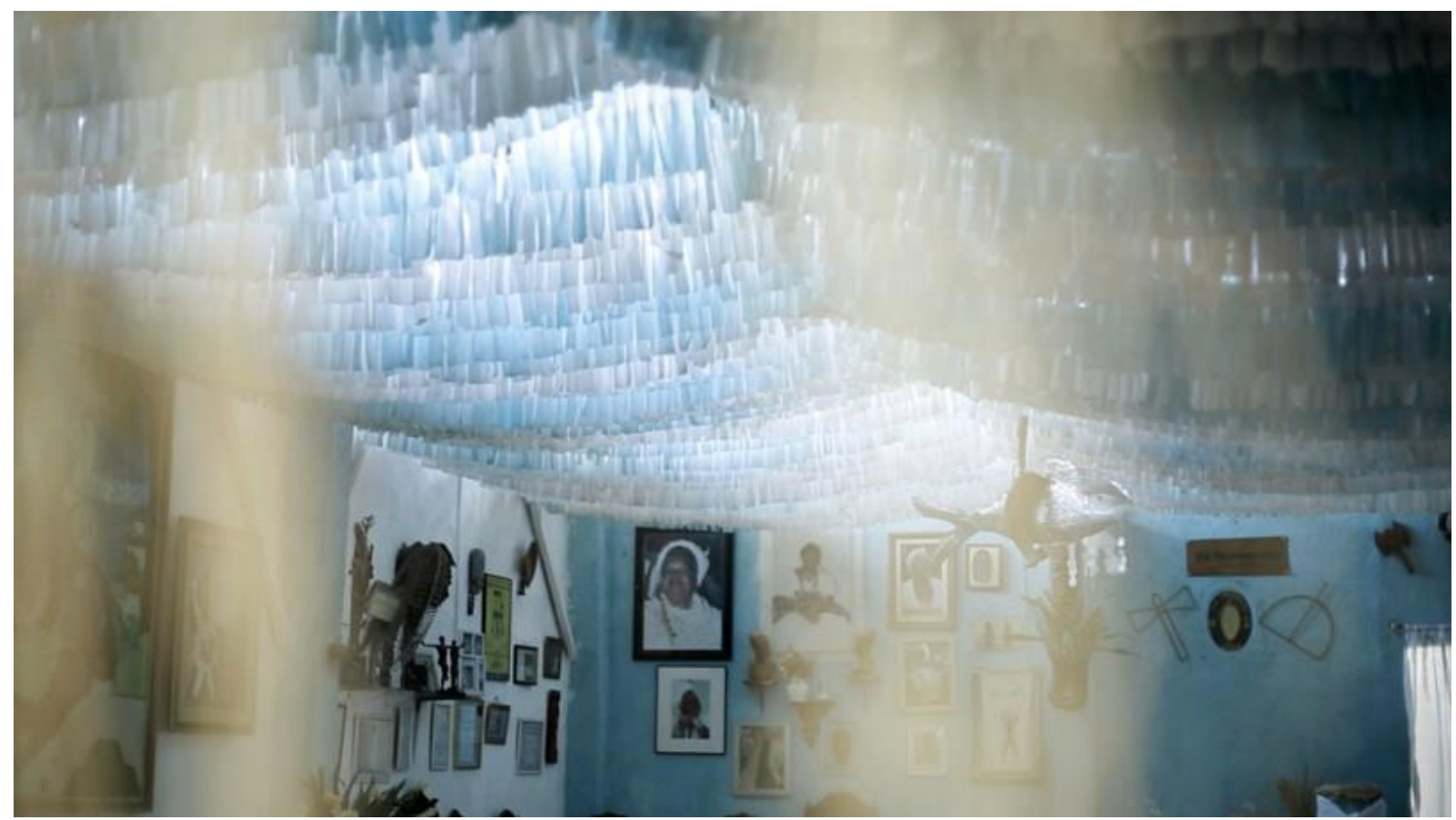

Figura 2. Terreiro

Fonte: Stela Caputo.

A palavra macumba sempre foi comum nos terreiros, podendo nomear o ritual, em si: "Vamos para a macumba?" "A macumba de ontem foi ótima!" Titulava também o próprio terreiro, o lugar da prática do culto: "A macumba de fulano ou beltrano", bem como, o poder religioso de alguém: "A macumba de sicrano ou sicrana é boa ou fraca". Nei Lopes (2003) ensina que o termo vem do quimbundo e também é uma espécie de reco-reco. 
Mantendo a origem do quimbundo, outro vínculo com a palavra, diz o pesquisador, vem de cumba, feiticeiro, com uma possível adição do prefixo plural ma. Ou seja, sendo instrumento ou designando diversos cultos afro-indígenas, a palavra habitava bem a boca dos macumbeiros (praticantes dos cultos aqui em questão). Se a palavra ficava mais guardada e segredada nos terreiros, era em função da perseguição racista, a palavra em si, não era rejeitada pelos adeptos.

No livro "Educação nos terreiros e como a escola se relaciona com as crianças de candomblé" (2012), Caputo, já nos evidenciava o uso do termo macumba para designar as práticas religiosas das religiões afro-brasileiras e o sentido pejorativo que essa palavra assume para além dos muros do terreiro e de seus iguais. Nas palavras da autora:

(...) No terreiro, muitos filhos e filhas de santo com os quais conversei, incluindo crianças e adolescentes, reconhecem que quando o termo é usado por pessoas que não pertencem ao candomblé, geralmente é pejorativo, mas quando usado por eles mesmos não assume essa conotação. Muitas vezes ouvi Ricardo Nery me pergunrar: "Vai ficar na macumba hoje?" Ou Paula Esteves brincar comigo: "Vai acabar virando macumbeira!" (...) (CAPUTO, 2012, p.43)

Na nota introdutória do livro "A ciência encantada das macumbas" (2018), Luiz Antonio Simas e Luiz Rufino, subvertendo os sentidos preconceituosos, nos explicam pela filosofia das ruas que:

Macumba seria, então, a terra dos poetas do feitiço, os encantadores de corpos e palavras que podem fustigar e atazanar a razão intransigente e propor maneiras plurais de reexistência pela radicalidade do encanto, em meio às doenças geradas pela retidão castradora do mundo como experiência singular de morte. (2018, p.7)

E mais:,

A macumba em um primeiro momento, seria aquilo que apresentaria as marcas da diversidade de expressões subalternas codificadas no mundo colonial, investidas de tentativas de controle por meio da produção do estereótipo. Encruzada a esta perspectiva, está a macumba como uma potência híbrida que escorre para um não lugar, transita como um "corpo estranho" no processo civilizatório, não se ajustando à política colonial e ao mesmo tempo o reinventando. Como signo ambivalente que é, desliza e encontra as frestas 
nos limites do poder, como potência do corpo que carrega em si parte possível de coexistência e de interpenetração. (SIMAS E RUFINO, 2018, p.15)

Nesses encantamentos e entrecruzamentos, pensamos as macumbas ${ }^{7}$, de perto ou de longe, boa ou fraca, como epistemologias dos saberes afrodiaspóricos, subvertidos nos espaçostempos dos terreiros, onde a colonização não se deixou aniquilar nem tampouco silenciar as vozes ancestrais, pelos seus ritos, seus cânticos, danças, toques, cheiros, e que hoje na nossa contemporaneidade, transborda para além dos muros dos terreiros, convergindo nas redes sociais.

Atualmente vemos muitas postagens nas redes sociais onde adeptos de candomblé procuram se afastar do termo macumba, assumindo o pejorativo no lugar da história, beleza e do significado da palavra, assumindo, enfim, uma autodepreciação, da qual falávamos, há pouco, com Fanon.

Entendemos que essa autodepreciação e afastamento na utilização do termo macumba desemboca numa encruzilhada de caminhos e percepções que ao mesmo tempo que segue na subversão dos ditames colonialistas ainda se percebe amalgamado pelo racismo estrutural da sociedade brasileira.

Mas o mesmo avanço das tecnologias, as mudanças nas dinâmicas comunicacionais em rede, também possibilitam táticas de luta antirracistas e a defesa do termo macumba irrompe na disputa por narrativas. As redes sociais são espaços que ganham protagonismo para difusão das religiões de matriz africana no Brasil, e que, cada vez mais, ampliam esse lugar que é o terreiro. (SANT'ANNA, SILVA, 2020)

Assim, os macumbeiros tem ressignificado sua atuação para além dos muros dos terreiros, compartilhado conhecimentos, histórias, reivindicações, autoafirmação e lutas.

\footnotetext{
${ }^{7}$ Adotamos o termo no plural, em consonância com as diferentes religiosidades de matriz africana no nosso país, especialmente os candomblés e as umbandas.
} 


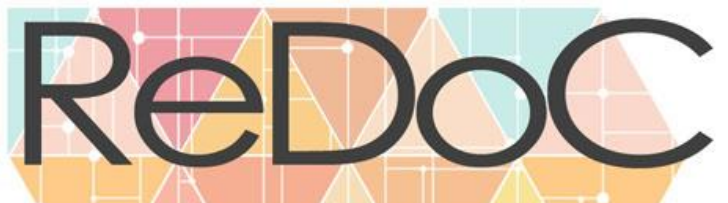

Revista Docência e Cibercultura

\section{CIBERCULTURA E O PROTAGONISMO DAS IMAGENS NAS REDES SOCIAIS}

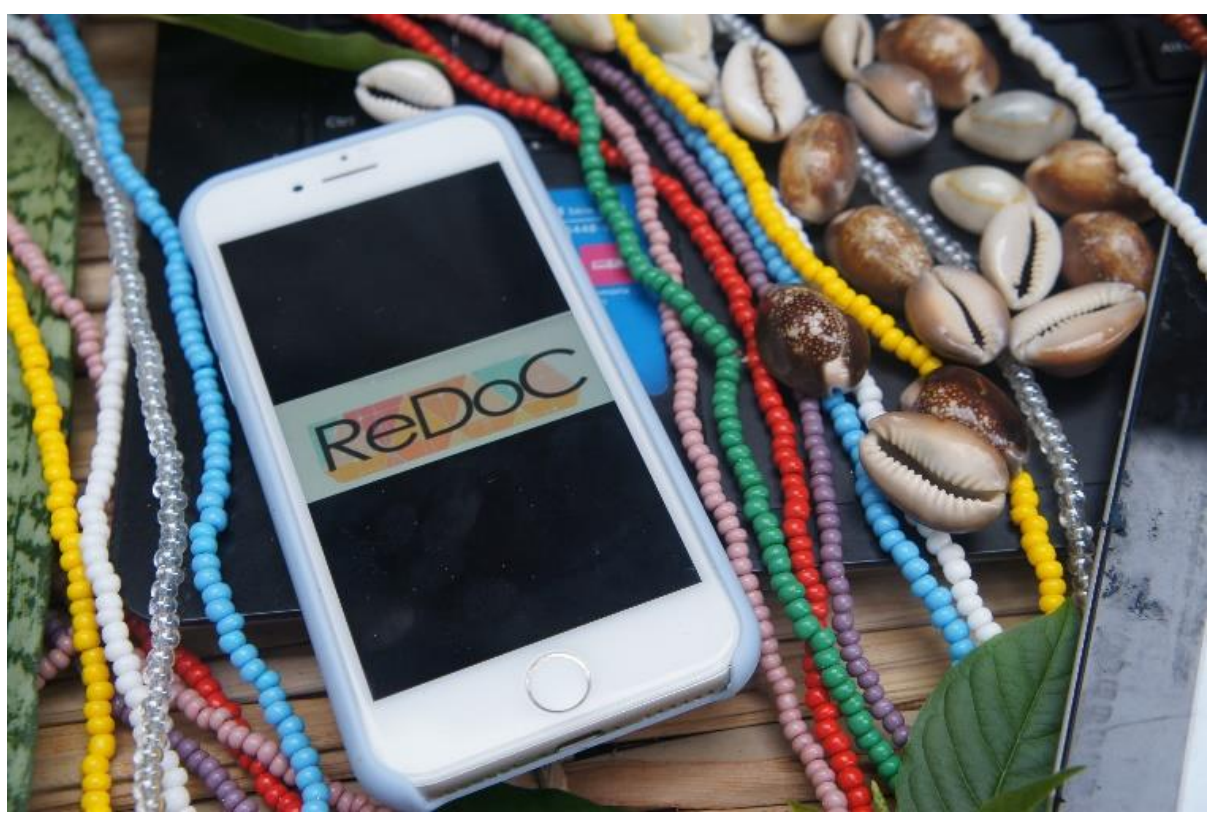

Figura 3. Macumba e cibercultura

Fonte: Cristiano Sant'Anna.

Na segunda década do século XXI, é quase impossível não conhecer ou ter ouvido falar em redes sociais da internet. Se pensamos com imagens e elas estão a nossa volta o tempo todo, podemos dizer quase o mesmo com as redes sociais, principalmente em tempos pandêmicos e de distanciamento social onde elas têm ocupado espaço de diversão e alento para muitos de nós.

Para além das redes sociais e do entretenimento que essas redes possam produzir no nosso cotidiano, não podemos deixar de lembrar que a cibercultura tem nos proporcionado diferentes ferramentas tecnológicas que vão além do prazer, para as diferentes atividades de trabalho, não só educacionais como também empresariais. ensino remoto, ensino híbrido, home office, são algumas modalidades urdidas na nossa contemporaneidade.

Compartilhamos com a pesquisadora Edméa Santos que:

A cibercultura é a cultura contemporânea mediada por tecnologias digitais em rede na relação cidadeciberespaço (SANTOS, 2005, 2014, 2019). Desde as práticas cotidianas vivenciadas pelo homem ordinário, que tece seu dia a dia, mais ou menos inventivo, no mais alto nível de desenvolvimento científico e tecnológico forjado por coletivos e instituições, tudo passa hoje por mediações diretamente ligadas ao digital em rede. Mais que nunca, a relação cidadeciberespaço vem sem 
instituindo por seres humanos em movimento, em trânsito. Trânsitos que rompem fronteiras físicas e simbólicas. Obviamente, não podemos esquecer os intensos níveis de exclusão digital, que não deixa de ser, também e sobretudo, existencial. (SANTOS, 2020. p.2)

As imagens e sua produção exponencial, são as grandes protagonistas da nossa contemporaneidade. Milhares de imagens são produzidas e consumidas continuamente, em processos digitais, promovidos pelo uso de câmeras nos diferentes modelos de smartphones disponíveis no mercado e publicadas nas redes sociais da internet. Nesse contexto o ato de clicar, postar, curtir, comentar e compartilhar se potencializam no nosso cotidiano, no que Sant'Anna, 2017 nos apresenta como "Sociedade do Compartilhamento".

Existe assim uma cultura da imagem difundida e vigiada pelas/nas redes sociais da internet, estabelecida por meio do compartilhamento nessas redes, tais como o Facebook, Instagram, Youtube, WhatsApp, dentre outras, articulando processos de uso, prazer, vigilância e visibilidade, entre seguidos e seguidores, como comumente são chamados e denominados os participantes das redes sociais.

Para além desses termos, acompanhamos Caputo e Sant'Anna, 2018 quando afirmam que os usuários das redes sociais da internet não são somente seguidores de páginas e perfis, mas "imaginantes". Pensamos com esses pesquisadores que: "a imaginação é a capacidade de criar, cocriar, esgarçar, subverter a lógica de todas as imagens e das intenções com as quais foram produzidas." (CAPUTO, SANT'ANNA, 2018, p. 154-155). Assim, entendemos que a participação nas redes sociais da internet, são urdidas em processos criativos, envoltos de constante mudanças e transformações.

No mundo onde a cibercultura tem ocupado um espaço cada vez mais atuante e relevante nos contextos sociais, políticos, econômicos e culturais da nossa sociedade, compreendemos as redes sociais da internet como "redes educativas" (ALVES,2008), e nesse contexto, espaçostempos de troca, aprendizagem e movimento, assim como as escolas, o cinema, os terreiros

Nesse processo contemporâneo, o que podemos observar é que, além da facilidade que a tecnologia tem nos proporcionado, para produção e consumo de imagens, as redes sociais da internet, dentre as já mencionadas acima, vêm facilitando a circulação, cada vez maior, de imagens do nosso cotidiano. Tudo é motivo para fotografar, registrar e também publicar.

Todas as relações que as redes sociais tem permitido, desde sua criação, e a potência que tem gerado na nossa atualidade é um fenômeno social que tem crescido continuamente e provocado 
mudanças até mesmo nas formas como nos relacionamos com o mundo a nossa volta, num verdadeiro processo de midiatização.

Entendemos que as religiões fazem parte dos processos sociais e culturais das sociedades, e com isso estão inseridas nas relações cotidianas advindos desses processos. Assim, temos observado que o fenômeno das redes sociais tem invadido o cotidiano das diferentes religiões e com isso os terreiros tem acompanhado esse movimento que se torna cada vez mais potente, acompanhando a atualidade e indo contra as proibições "impostas" pelas tradições.

Nas diferentes redes sociais, encontramos uma multiplicidade de páginas relacionadas às religiões de matriz africana. São fotografias, mensagens de Orixás e Guias, vídeos de saídas de santo, páginas de Ogans - cargo masculino que tem função principal o toque dos atabaques, de ekedis - cargo feminino nas religiões de matriz africana de cuidado aos Orixás, até mesmo páginas de terreiros e/ou sites. Uma profusão de imagens quer sejam fotografias ou mesmo audiovisuais são publicadas nessas redes.

As imagens divulgadas pelos terreiros e seus adeptos também nos mostram a importância e a afirmação da religião que desde os primórdios foi envolta de perseguição e discriminações. Entendemos, assim, como uma tentativa de derrubar as barreiras do racismo religioso que a cada dia tem se intensificado nas nossas relações sociais cotidianas, urdidas por uma onda conservadora no nosso país.

Nesse diálogo, esses novos espaços sociais, popularizados e protagonizados através dos fenômenos da cibercultura, podem ser usados como estratégias de luta antirracista, especificamente o racismo religioso.

Pensamos para esse dossiê, artigos e pesquisas que versam sobre religiosidades afrodiaspóricas e nos seus entrecruzamentos com os fenômenos da ciberculturas, tais como as redes sociais da internet, bem como racismo, racismo religioso, história e cultura africana e afro-brasileira.

Cristiano Sant'Anna, Isadora Souza e João Vitor Ferreira abrem o dossiê com o texto Ogumorixá da internet: forjando as redes sociais como ferramentas de luta antirracista associando os saberes ancestrais, em específico dessa divindade, às ferramentas e estratégias tecnológicas e comunicacionais na contemporaneidade. $\mathrm{O}$ artigo tem o objetivo de denominar diferentes dispositivos tecnológicos como "ferramentas tecnológicas" e "metodologias de Ogum", ressaltar a importância e a influência da tecnologia, das imagens e da Cibercultura no nosso cotidiano, bem como nas práticas de pesquisas em tempo de pandemia e, dessa forma, forjar as redes sociais da internet como ferramentas de luta antirracista.

Ozaias da Silva Rodrigues em $\mathbf{O}$ candomblé sob a mira do racismo e do terrorismo religioso: ataques, categorias e identidades reinventadas traz ao debate os ataques contra as 
religiões afro e tenta compreender quais categorias sustentam tais atos de violência, e como elas reverberam nas construções identitárias de seus adeptos.

Tiago Dionisio da Silva, em As relações raciais na educação de jovens e adultos trabalhadores: desafio à ciência geográfica busca refletir sobre a interseccionalidade entre classe e raça no contexto da sociedade brasileira que atravessa o sistema educacional para compreender a demanda e a manutenção da Educação de Jovens e Adultos (EJA) caracterizadas por trabalhadores e negros. Observando a necessidade de olhar para a EJA como um campo educacional marcado pela exclusão social e racial.

Em Terreiro e produção de epistemologias decoloniais: narrativas de um pesquisadorfilho de santo, Jóse Augusto dos Reis Neto apresenta as "com-vivências" de um pesquisadorfilho de santo em sua comunidade com o objetivo de refletir sobre como o terreiro anuncia outras possibilidades de existências, conhecimentos e educaçõese como essa relação pode impactar na produção do conhecimento, na produção (e resgate) de outras epistemologias e na construção de uma perspectiva decolonial para a educação e a práxis de pesquisa.

Gustavo Jaime Filizola e Aurino Lima Ferreira apresentam em Processos de formação humana: I Encontro de crianças de Axé depoimentos sobre as experiências do I Encontro Nacional de Crianças de Axé no ano de 2017 em - Paulista - Pernambuco. Os objetivos do encontro foram conversar com as crianças sobre os conhecimentos oriundos das tradições religiosas do candomblé, assim como, debater o preconceito que ainda existe, inclusive, nas escolas,onde foi possível fazer uma análise tomando como base os estudos decoloniais e perceber que a ancestralidade, a oralidade e componentes comunitários consolidam os processos de formação humana das crianças de terreiro numa perspectiva bio, psico, cognitivo, sócio-cultural, associada à dimensão espiritual.

O ensino afroperspectivista em sala de aula por um olhar outra da educação, Denis Harmony da Silva apontam que mesmo com da implementação da Lei nº $10.639 / 03$, alterada pela Lei $\mathrm{n}^{\circ} 11.645 / 08$, que tornou e reiterou a inclusão do Ensino de História e Cultura Afrobrasileira e Africana em todos os currículos escolares do país é possível reconhecer sem grandes esforços que ainda há um 'estranhamento' em práticas didático-pedagógicas, especialmente, por parte dos professores, para a efetividade do trabalho educativo que atenda as expectativas e as demandas das múltiplas negritudes invisibilizadas, marginalizadas e, quase, silenciadas nas cidades, periferias, morros e favelas. Em seu artigo, o autor aponta a necessidade de propor uma reflexão acerca de novas alternativas didáticas e metodológicas na sala de aula, pautadas nas visibilidades e no reconhecimento da produção de conhecimento e da circularidade dos saberes dos negros africanos e seus descendentes (afro-brasileiros). 
Em Entre a regularidade e o desafio da aplicação da lei 10.639/03: o ressoar e a resitência dos tambores no trato pedagógico, Waldinéia Teles Pereira, Renato Alves de Carvalho Júnior levantam uma série de questionamentos históricos acerca da regularidade e os inúmeros desafios de tratar pedagogicamente a História da África e dos Africanos, a luta dos negros no Brasil, a cultura negra brasileira e o negro na formação da sociedade nacional, resgatando a contribuição do povo negro nas áreas social, econômica e política pertinentes à História do Brasil. No artigo texto, autores apresentam o elemento Tambor como o grande mediador do embalo das nossas raízes ancestrais tão presentes em nossas vidas, nos chamando para aprender com plenitude e consciência.

Adelson Cezar Ataíde Costa Junior, em Pela boca da criança: pensando gênero e sexualidade a partir da infância de terreiro apresenta a investigação sobre as práticas educativas imbricadas com as relações de gênero e sexualidade em um terreiro de candomblé de nação Ketu, em Ananindeua - Pará. Levando em conta os estudos feministas e de relações de sexo atuais, o autor busca entender os processos pelos quais as relações de sexo/gênero servem como fatores de afirmação identitária,atentando também para uma participação das crianças no processo de discussão desse debate.

Em Macumba em escola pública no interior sergipano: Tranca-Rua visita escola de ensino médio em tempo integral, Jaime Rodrigues Da Silva, Cláudia Regina Cardoso Rodrigues da Silva e Bárbara Regina Cardoso Rodrigues da Silva apresentam como um grupo de alunos, praticantes do culto afro-brasileiro da Umbanda e do Candomblé, fizeram sobre a discriminação que sofriam em uma escola pública de EMTI no interior sergipano, após a implantação de um "Clube de Protagonismo", intitulado "Clube da Bíblia". Autores narram a apresentação à comunidade escolar do "Sr. Tranca Rua", "entidade/divindade" tantas vezes marginalizada e erroneamente associada ao diabo pelos neopentecostais.

No artigo Maíra Azevedo: uma influenciadora digital na rede ciberaxé, Lúcio André Andrade da Conceição apresenta Maira Azevedo, influenciadora digital com notoriedade em várias plataformas virtuais, discutindo temas relacionados ao candomblé, mulher negra, dentre outros tópicos. |Conceitos de virtualidade e subjetividade são acionados em diálogo, com a compreensão teórica de Exu, sob duas perspectivas: uma, enquanto símbolo que representa a comunicação, via ciberespaço, como sendo "boca que tudo come"; a outra, como fragmentos de pensamento de um coletivo e tradutor de uma compreensão de mundo fora dos cânones ocidentais.

Lílian Carine Madureira Vieira da Silva, Rita Cristine Basso Soares Severo em Educação para as relações étnicos: possibilidades da educação e um currículo antirracista? discute a Educação para as Relações Étnico-Raciais como a possibilidade de construção de um currículo e, uma escola antirracista. Uma forma de combater o racismo na escola e garantir a efetiva 


\section{Revista Docência e Cibercultura}

implementação de uma Educação para as Relações Étnico-Raciais, pautada pela igualdade e equidades entre os sujeitos.

Em Fé e resistência: por uma teologia de respeito, Jorge Luís Rodrigues dos Santos, Matheus Motta dos Santos aponta a ocorrência de casos de intolerância religiosa, que no caso particular do Brasil, multiplica-se e destaca-se as violências e agressões sofridas por praticantes e estabelecimentos de cultos afro-brasileiros. Acreditando ser urgente e necessária a reflexão sobre a construção de uma sociedade que tenha a diversidade e a pluralidade como valores inalienáveis, e o respeito em relação ao direito de expressar uma religiosidade com liberdade e sem restrições. $\mathrm{O}$ autor pondera que se deve exigir é o respeito, enquanto um dever como cidadão da comunidade planetária humana.

Daise Santos Pereira, Marcia Guerra Pereira, Alana Alves Pereira e Maria Cecília Ribeiro Paixão em Luta antirracista ne educação infantil em tempos de pandemia: o que as táticas docentes revelam? traz uma discussão atual e emergente, a opção pela continuidade do ano letivo de 2020, na forma remota emergencial no Estado do Rio de Janeiro, resultou de deliberação político-administrativa exclusiva das instâncias de governo, cuja aplicação não foi acompanhada de um debate amplo e participativo na sociedade e, em particular, entre os profissionais de ensino, responsáveis pelos discentes e comunidade acadêmica. O artigo apresenta táticas usadas por professores da educação infantil do município de Magé para uma educação antirracista, em meio às inadequações das instituições, realidades locais e as limitações de atendimento mínimo dos objetivos previstos na legislação brasileira relativos a cada nível de ensino.

Em A Lei 10639 e sua maior idade. Há o que se comemorar? Leonor Franco Araújo nos convida a refletir sobre os caminhos percorridos pela Lei 10639/2003 nos seus 18 anos de promulgação, principalmente a partir da gestão da Coordenação de Educação para a Diversidade da Secretaria de Educação Continuada, Alfabetização e Diversidade , hoje Coordenação de Educação Étnico-Racial, e a elaboração do Plano Nacional para Implementação das Diretrizes Curriculares Nacionais para a Educação das Relações ÉtnicoRaciais e para o ensino de História e Cultura Afro-Brasileira e Africana.

\section{REFERÊNCIAS}

ARAUJO, Leonor Franco. A Lei 10639 e sua maior idade. Há o que se comemorar? Revista Docência e Cibercultura, v. 5, n. 2, maio-ago, 2021, p. 279-294.

DOI: https://doi.org/10.12957/redoc.2021.57479 
CAPUTO, Stela Guedes. Educação nos terreiros: e como a escola se relaciona com crianças de candomblé. Rio de Janeiro: Pallas, 2012.

CÉSAIRE, Aimé. Discourse on Colonialism [1950]. Traduzido por Joan Pinkham. Nova Iorque: Monthly Review Press, 2000.

CONCEIÇÃO, Lúcio André Andrade da. Maíra Azevedo: uma influenciadora digital na rede ciberaxé. Revista Docência e Cibercultura, v. 5, n. 2, maio-ago, 2021, p. 217-242.

DOI: https://doi.org/10.12957/redoc.2021.57122

COSTA JUNIOR, Adelson Cezar Ataide. Pela boca da criança: pensando gênero e sexualidades a partir da infância de terreiro. Revista Docência e Cibercultura, v. 5, n. 2, maio-ago, 2021, p. 182-198. DOI: https://doi.org/10.12957/redoc.2021.56620

CAPUTO, Stela Guedes; e SANT'ANNA, Cristiano. "Ninguém é seguidor, somos todos imaginantes", in: VIDAL, H. e UCELLI, M. (orgs.). Educação, comunicação, cultura e diferença. Vitória: Pedregulho, p. 143-156, 2018.

FILIZOLA, Gustavo Jaime; FERREIRA, Aurino Lima. Processos de formação humana: I encontro nacional de crianças de axé. Revista Docência e Cibercultura, v. 5, n. 2, maio-ago, 2021, p. 128-149. DOI: https://doi.org/10.12957/redoc.2021.56594

MILLER, Joseph - Revista de História da Biblioteca Nacional - edição nº 10 - Julho 2006.

MEDEIROS, Cristiano Sant'Anna de; SILVA, Isadora Souza da; FERREIRA, João Victor Gonçalves. Ogum - orixá da internet: forjando as redes sociais como ferramentas de luta antirracista. Revista Docência e Cibercultura, v. 5, n. 2, maio-ago, 2021, p. 31-50.

DOI: https://doi.org/10.12957/redoc.2021.57207

SANT'ANNA, Cristiano. \#DIFERENÇA: pensando com imagens dentrofora da escola. 2017. 195 f. Tese (Doutorado em Educação) - Programa de Pós-Graduação em Educação (Proped), Universidade do Estado do Rio de Janeiro (UERJ), Rio de Janeiro, 2017. Disponível em: http://www.proped.pro.br/teses/teses_pdf/2007_1-266-DO.pdf. Acesso em: 10 fev. 2021.

SANT'ANNA, Cristiano. "Terreiros, crianças e imagens numa sociedade do compartilhamento", in: CABRAL, B. M. e ALBUQUERQUE, B. S. (orgs.). $3^{\circ}$ Simpósio sudeste da ABHR: laicidade e pluralismo. Educação, Religiosidade e Direitos Humanos. Rio de Janeiro: Autografia, pp. 41-57, 2020.

SANT'ANNA, Cristiano; SILVA, Isadora Souza da. Pensando diferença religiosa no combate ao racismo religioso. PLURA, Revista de Estudos de Religião, v. 11, n. 1, p. 128-143, 2020. Disponível em: https://revistaplura.emnuvens.com.br/plura/issue/view/30. Acesso em: 12/032/2021. 
NETO, João Augusto dos Reis. Terreiro e produção de epistemologias decoloniais: narrativas de um pesquisador-filho de santo. Revista Docência e Cibercultura, v. 5, n. 2, maio-ago, 2021, p. 98-127. DOI: https://doi.org/10.12957/redoc.2021.56453

PEREIRA, Daise Santos; PEREIRA, Marcia Guerra; PEREIRA, Alana Alves; PAIXÃO, Maria Cecília Ribeiro. Luta antirracista na educação infantil em tempos de pandemia: o que as táticas docentes revelam? Revista Docência e Cibercultura, v. 5, n. 2, maio-ago, 2021, p. 259-278. DOI: https://doi.org/10.12957/redoc.2021.57270

PEREIRA, Waldinéia Teles; e CARVALHO JÚNIOR, Renato Alves de. Entre a regularidade e o desafio da aplicação da lei 10.639/03: o ressoar e a resistência dos tambores no trato pedagógico. Revista Docência e Cibercultura, v. 5, n. 2, maio-ago, 2021, p. 169-181. DOI: https://doi.org/10.12957/redoc.2021.56608

RODRIGUES, Ozaias Silva. O candomblé sob a mira do racismo e do terrorismo religioso: ataques, categorias e identidades reinventadas. Revista Docência e Cibercultura, v. 5, n. 2, maio-ago, 2021, p. 51-72. DOI: https://doi.org/10.12957/redoc.2021.56317

SANTOS, Jorge Luís Rodrigues dos; SANTOS, Matheus Motta dos. Fé e resistência: por uma teologia do respeito. Revista Docência e Cibercultura, v. 5, n. 2, maio-ago, 2021, p. 262-258. DOI: https://doi.org/10.12957/redoc.2021.57183

SILVA, Denis Harmony da; SOARES, Cecília Conceição Moreira. O ensino afroperspectivista em sala de aula por um olhar outro da educação. Revista Docência e Cibercultura, v. 5, n. 2, maio-ago, 2021, p. 150-168.

DOI: https://doi.org/10.12957/redoc.2021.56606

SILVA, Jaime Rodrigues da; SILVA, Cláudia Regina Cardoso Rodrigues da; SILVA, Bárbara Regina Cardoso Rodrigues da. Macumba em escola pública no interior sergipano Tranca Rua visita escola de ensino médio em tempo integral. Revista Docência e

Cibercultura, v. 5, n. 2, maio-ago, 2021, p. 199-216.

DOI: https://doi.org/10.12957/redoc.2021.56720

SILVA, Lílian Carine Madureira Vieira da; SEVERO, Rita Cristine Basso Soares. Educação para as relações étnico-raciais: possibilidade da educação e um currículo antirracista? Revista Docência e Cibercultura, v. 5, n. 2, maio-ago, 2021, p. 243-261.

DOI: https://doi.org/10.12957/redoc.2021.57148

SILVA, Tiago Dionisio da. As relações raciais na educação de jovens e adultos trabalhadores: desafios à ciência geográfica. Revista Docência e Cibercultura, v. 5, n. 2, maio-ago, 2021, p. 73-97. DOI: https://doi.org/10.12957/redoc.2021.56421 


\section{Agradecimentos}

Agradecemos a todos, todas e todes que partilharam seus saberes, suas pesquisas, para compor esse dossiê, que agora compartilhamos com toda comunidade acadêmica e não acadêmica.

Entendemos que receber e compartilhar é uma dádiva potente que nos move e nos fortalece nas lutas diárias contra as discriminações.

Como um curso d'água, que possamos passar pelas grandes e pequenas frestas e encontrar diferentes caminhos, subverter a ordem dada e seguir na luta.

Os autores

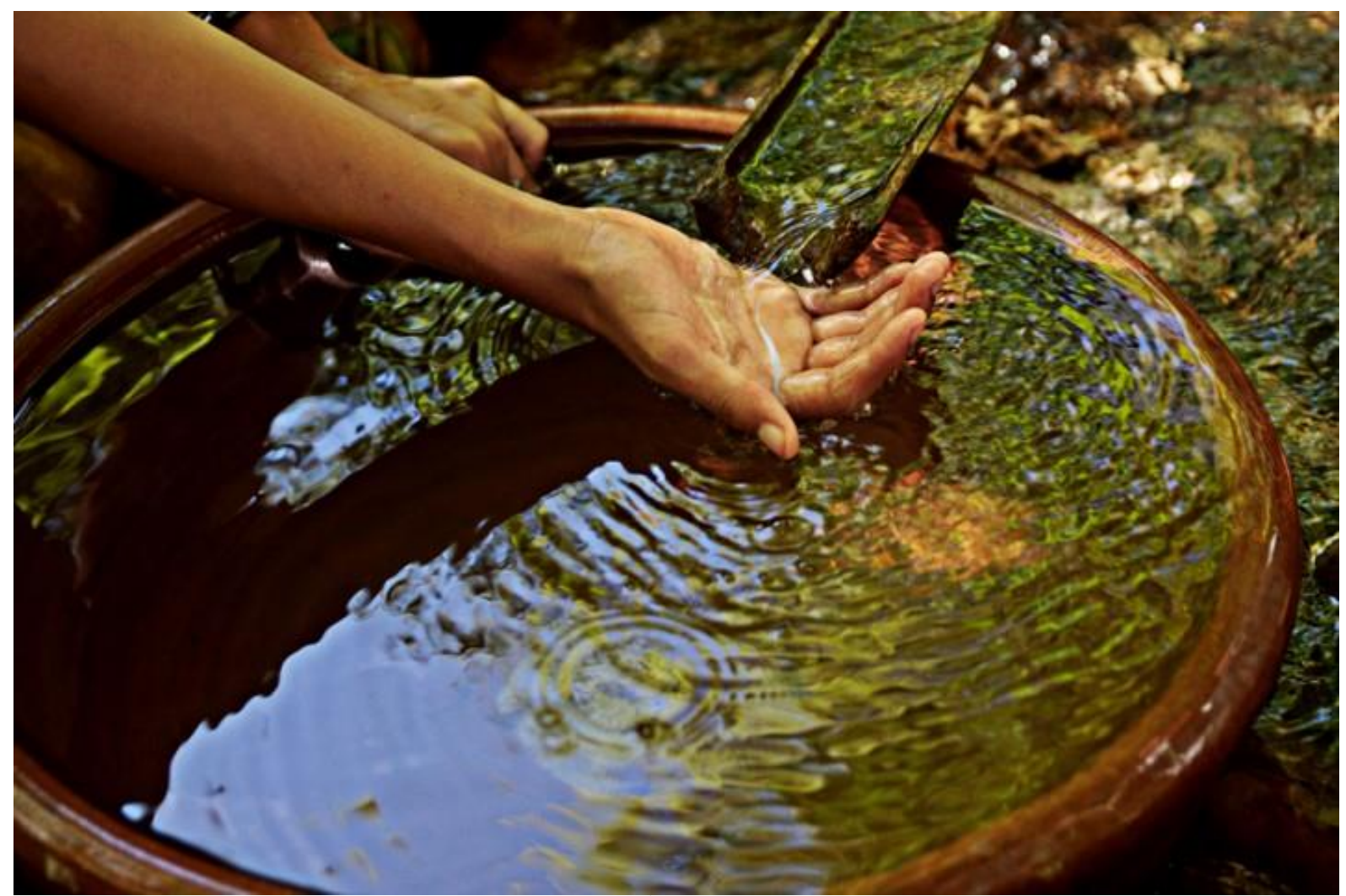

Figura 4. Água, vida e axé

Fonte: Stela Caputo.

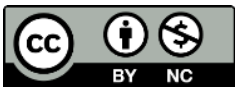

Este é um artigo de acesso aberto distribuído sob os termos da Licença Creative Commons Atribuição Não Comercial-Compartilha Igual (CC BY-NC- 4.0), que permite uso, distribuição e reprodução para fins não comerciais, com a citação dos autores e da fonte original e sob a mesma licença. 